\title{
UMA PROPOSIÇÃO METODOLÓGICA PARA COMPREENDER A EXPERIMENTAÇÃO EM CIÊNCIAS NA EAD
}

\author{
V. HECKLER ${ }^{*}$, C. S. MOTTA, A. M. DORNELES E M. C. GALIAZZI \\ Universidade Federal do Rio Grande - FURG \\ valmirheckler@furg.br*
}

Artigo submetido em março/2013 e aceito em dezembro/2014

DOI: $10.15628 /$ holos.2014.2047

\section{RESUMO}

Neste artigo apresentamos uma proposição metodológica com o objetivo de expressar compreensões sobre a experimentação em Ciências na Educação a Distância (EaD). Inicialmente desenvolvemos a disciplina Experimentação em Ciências na EaD no Programa de Pós-Graduação Educação em Ciências (PPGEC) da Universidade Federal do Rio Grande (FURG). Esta envolveu professores, de diferentes níveis de ensino, com formações em Química, Biologia e Física. A pesquisa é qualitativa de natureza fenomenológica hermenêutica com a análise de dados pela Análise Textual Discursiva (ATD). Sistematizamos em unidades de significados, interlocuções teóricas e evidências empíricas, a partir dos registros expressos no ambiente virtual de aprendizagem (AVA) da disciplina. Significamos a disciplina como espaçotempo de pesquisa-formação online com base na linguagem, em que o coletivo de professores busca compreender e desenvolver a experimentação em Ciências.

PALAVRAS-CHAVE: Experimentação em Ciências, EaD, pesquisa-formação online, pesquisa qualitativa, objeto aperfeiçoável.

\section{A METHODOLOGICAL PROPOSAL FOR UNDERSTAND THE EXPERIMENTATION OF SCIENCES IN DISTANCE EDUCATION}

\begin{abstract}
This article presents a methodological proposal with objective to express understandings about the experimentation in Sciences in Distance Education (DE). Initially we developed the discipline Experimentação em Ciências na $E a D$ in the Programa de Pós-Graduação Educação em Ciências (PPGEC) the Universidade Federal do Rio Grande (FURG). This involved teachers from different educational levels, with formation in Chemistry, Biology and Physics. The research is qualitative the nature phenomenological hermeneutic with data analysis by
\end{abstract}

Análise Textual Discursiva (ATD). For that, the dialogues theoretical and empirical are systematized in units of meaning from the records expressed in the virtual environment of discipline. The discipline is spacetime research-formation online of a collective of teachers who search simultaneously understand and do the experimentation in sciences. We understand the discipline as spacetime research-formation online based in language in which a collective of teachers seeks to understand and develop experimentation in Science.

KEYWORDS: Experimentation in Sciences, distance education - DE, research-formation online, qualitative research, improvable object. 


\section{INTERLOCUÇÃO INICIAL}

O presente artigo aborda o desenvolvimento metodológico da investigação de um projeto de doutoramento, o qual iniciou no grupo de pesquisa $\mathrm{CEAMECIM}^{1}$, em que desenvolvemos, durante o segundo semestre de 2011, a disciplina Tópicos Especiais - Experimentação em Ciências na Educação a Distância (EaD).

A referida disciplina foi ofertada pelo Programa de Pós-Graduação Educação em Ciências (PPGEC) da Universidade Federal do Rio Grande (FURG), frente à iminente oferta do curso de Licenciatura em Ciências na modalidade a distância. Esta envolveu doze professores, dentre estes: pós-graduandos, professores da rede de ensino da Educação Básica e docentes da Universidade, com formações nas Licenciaturas em Química, Biologia e Física. Ao longo da escrita, significamos a disciplina como espaçotempo ${ }^{2}$ de pesquisa-formação online ${ }^{3}$ de um coletivo de professores da Experimentação em Ciências na EaD. A disciplina foi estruturada em 10 semanas de atividades via Plataforma Moodle ${ }^{4}$ da Secretaria de Educação a Distância - SEaD da FURG, com auxílio do software de webconferência Adobe Connect ${ }^{5}$, e em encontros presenciais. Assumimos o ambiente investigado como "objeto aperfeiçoável" ${ }^{6}$ (WELLS, 2009, p. 289) do qual emergem as evidências empíricas expressas neste artigo.

Assumimos a pesquisa qualitativa de cunho fenomenológico hermenêutico (BICUDO, 2011), a escrita baseada em interlocuções teóricas e empíricas com o objetivo de compreender o fenômeno da experimentação em Ciências na EaD. Além disso, evidenciamos no texto as formas utilizadas no complexificar argumentos, a partir da análise dos dados, realizada com base na Análise Textual Discursiva (ATD) (MORAES; GALLIAZZI, 2011).

Apostamos que a imersão dos professores na disciplina oportuniza operar atividades e ressignificar os discursos imersos na linguagem ao promover indagação dialógica entre diferentes interlocutores. Assim, constituímos o ambiente de investigação ao promovermos questionamentos e análises das diferentes linguagens expressas pelos sujeitos. Nesse momento, articulando a ação do compreender à ação de atuar na experimentação em Ciências na EaD.

Apresentamos, inicialmente, no item dois, entendimentos em torno do objeto aperfeiçoável, em que os professores operam a experimentação em Ciências como uma "sala de

\footnotetext{
${ }^{1}$ Grupo de Pesquisa CEAMECIM/FURG - Comunidades Aprendentes em Educação Ambiental, Ciências e Matemática.

${ }^{2}$ Espaçotempo - Conforme as ideias de Alves (2012), utilizaremos a grafia espaçotempo, ao longo do texto, "para contrapor-se às práticas que, criadas na modernidade, nos obrigam à dicotomização da realidade". Diniz-Pereira e Lacerda (2009) assumem o referido termo para atribuir simultaneidade em processos de pesquisa/formação com professores da escola, reconhecendo estes profissionais como sujeitos participantes do processo de investigação e não, apenas, "tratando-os" como "objetos de análise".

${ }^{3}$ Online - Desenvolvemos interlocução teórica com Silva e Santos (2006) e Silva (2012) sobre a mediação da aprendizagem a partir das possibilidades da web 2.0. O termo online é usado no sentido de envolver os docentes e os estudantes em ambientes de aprendizagem em um processo coletivo de formação, com relações horizontais abertas à colaboração e à coautoria, o que possibilita a cocriação da comunicação e do conhecimento.

${ }^{4}$ Moodle - Modular Object Oriented Dynamic Learning Environment - é um software livre de apoio à aprendizagem, disponibilizado em um Ambiente Virtual de Aprendizagem. A FURG disponibiliza esse ambiente virtual para diferentes modalidades de ensino. Disponível em: <http://www.moodle.org >.

${ }^{5}$ Adobe Connect - software utilizado para desenvolver webconferência, que possibilita promover encontros virtuais entre sujeitos de diferentes locais, distantes geograficamente.

${ }^{6}$ Objeto aperfeiçoável - tradução livre, do inglês para o português, de “improvable object" de Wells (2009, p. 289).
} 
aula online" (SILVA; SANTOS, 2006), imersos na linguagem. Assumimos a linguagem pela abordagem sociocultural como artefato utilizado pelos sujeitos, fundamental no organizar, no desenvolver a construção do conhecimento e no registrar compreensões das aprendizagens, por interpretarmos o diálogo pela fala, escrita, leitura e escuta como ações de imersão dos sujeitos na linguagem. No item três, dialogamos sobre as evidências empíricas iniciais desenvolvidas pelos sujeitos ao operarem atividades na Experimentação em Ciências na EaD como objeto aperfeiçoável, envolvendo compreensões a respeito das temáticas trabalhadas, dos artefatos, das interfaces tecnológicas e das atividades realizadas na disciplina.

No item quatro dessa escrita, apresentamos o caminho para complexificar os argumentos no compreender a experimentação em Ciências na EaD, tornando-se ferramenta epistêmica para análise das informações na pesquisa qualitativa. Nesse estudo, as informações são produzidas e, posteriormente, analisadas pela ATD ao se investigar o ambiente coletivo desenvolvido pelos professores de Ciências. A ATD consiste em construir unidades de significado, categorias e produção textual sobre o fenômeno nesse caso o da experimentação em Ciências na EaD. Apresentamos, no final do texto, a síntese do mergulho dos pesquisadores na análise de informações em torno das compreensões desenvolvidas.

\section{COMPREENDER O OBJETO APERFEIÇOÁVEL COM SUJEITOS IMERSOS NA LINGUAGEM EM PESQUISA-FORMAÇÃO ONLINE}

Considerar a imersão dos sujeitos na linguagem em sala de aula online é assumi-la como principal ferramenta dos seres humanos na mediação conjunta de suas atividades e implica em percebermos suas caminhadas desde o surgimento da fala acerca de 50.000 anos atrás (WELLS, 2009). Além disso, se torna um movimento de refletir sobre nossa apropriação da linguagem e como ela pode ser utilizada no desenvolver e socializar habilidades e conhecimentos para as gerações seguintes. Nessa perspectiva, o falar, escrever e ler são mediadores da cultura e, ao mesmo tempo, do desenvolvimento social e intelectual de cada indivíduo.

Para depreender a linguagem como artefato fundamental na organização e no desenvolvimento dos processos de pensamento, ancoramo-nos na abordagem sociocultural. Diante disso, afirmamos que tanto os artefatos mentais quanto os físicos utilizados pelos sujeitos, como, por exemplo, a fala, são formas de "[...] dominar seu ambiente e seu próprio comportamento" (VIGOTSKI et al., 2012, p. 26). Segundo o mesmo autor, outras ferramentas foram inventadas e aperfeiçoadas ao longo da história social do homem. Exemplo disso é a escrita, que oportuniza registrar a "[...] sabedoria do passado analisável no presente e passível de aperfeiçoamento no futuro" (VIGOTSKI et al., 2012, p. 27).

Com isso, assumimos, a partir de Wells (1999), Vigotski (2012), Marques (2008) e Moraes (2007), a linguagem como artefato epistêmico da pesquisa-formação online de professores para uma abordagem sociocultural na experimentação em Ciências na EaD. Para tanto, é imprescindível também pensarmos nos espaços de sala de aula nas diferentes modalidades de ensino, de forma que envolvam os sujeitos a expressarem seus pensamentos, seus sentimentos e suas ações através da fala, escrita e leitura, no sentido de construir aprendizagens individualmente ou no coletivo. Para a experimentação em Ciências no contexto online, propomos o diálogo como forma de imersão dos sujeitos na linguagem, para que, a partir desta, 
compreendemos que, por meio dos diferentes discursos emergentes em grupos, desenvolvem-se as aprendizagens.

Construir aprendizagem na pesquisa-formação de professores em Ciências pela imersão na linguagem é considerarmos que "[...] aprender requer movimentar-se na linguagem e aprende-se a partir das interações na linguagem, uma forma de ampliar fronteiras e detalhar cada vez mais os mapas já produzidos" (MORAES, 2007, p. 31). O reconhecimento do que deve ser desenvolvido e da forma como isso será realizado nas atividades de experimentação em Ciências na EaD instiga os pesquisadores a proporem a construção de um caminho metodológico que possibilite a análise das linguagens expressas pelos sujeitos em pesquisa-formação no operar das atividades da sala de aula online. As linguagens expressas pelo coletivo de professores e registradas nas interfaces do ambiente virtual Moodle da disciplina e, posteriormente, coletadas são as evidências empíricas desse estudo.

Esse espaçotempo de escrever sobre a experiência vivenciada possibilita-nos assumi-la como pesquisa-formação online de professores de Ciências. Estamos incluídos nesse coletivo de professores e, assim, constituímo-nos sujeitos ativos e em processo formativo na ação de transformar práticas no ambiente investigativo das atividades experimentais em Ciências para a modalidade a distância. Sendo assim, traçamos o caminho metodológico de imergir sujeitos em "pesquisa-formação" como um espaço para modificar práticas sociais e de formação dos professores que compõem o respectivo ambiente (SILVA, 2012). Cada pessoa envolvida na disciplina é, ao mesmo tempo, objeto e sujeito da formação, na busca por articular ações entre o compreender e o atuar na experimentação em Ciências na EaD.

A disciplina foi estruturada em 10 semanas de atividades organizadas na plataforma Moodle da Secretaria de Educação a Distância da FURG com o auxílio do software de webconferência Adobe Connect e de encontros presenciais. Esta teve o propósito de possibilitar aos participantes um espaço para que pudessem dialogar, indagar, propor, teorizar, praticar e ser sujeitos ativos no transformar do outro e em sua transformação de percepções sobre a experimentação em Ciências. Nessa proposição, assumimos a abordagem sociocultural no sentido de que a "transmissão racional e intencional da experiência e pensamento de cada sujeito requer um sistema mediador" em função da necessidade do intercâmbio social, estabelecido pela fala, escrita, leitura e pelo operar das atividades propostas (VIGOTSKI, 2008, p. 7).

Tomamos a escrita recursiva na pesquisa qualitativa fenomenológica hermenêutica como forma metodológica dos movimentos coletivos dos professores/investigadores imersos. Durante os encontros do grupo de pesquisa, diferentes momentos de escrever, comunicar coletivamente metatextos, efetuar diálogos e leituras auxiliaram a complexificarmos compreensões do que nos instiga/instigou e move enquanto questão central de pesquisa. Esse momento se torna importante na investigação "[...] para o pesquisador que, ao estar com seu grupo de pesquisa, vive as idas e vindas das incertezas e certezas, bem como a necessidade de escrever e modificar o escrito nova e novamente, por um espaço temporal não passível de mensuração" (BICUDO, 2011, p. 41).

Nessa perspectiva, o estar em movimento coletivo no grupo de pesquisa em Ciências, com e pela escrita, oportuniza reconstruirmos a questão central da pesquisa, a qual, em agosto de 2011, era: como poderemos, enquanto docentes, construir e desenvolver atividades 
experimentais em um curso de Licenciatura em Ciências na EaD? Modificamos a questão central da investigação no momento em que avançamos, no grupo de pesquisa CEAMECIM, a leitura sobre "objeto aperfeiçoável" em uma abordagem sociocultural (WELLS, 2009). Compreendemos os objetos aperfeiçoáveis como diferentes artefatos (material e simbólico) - a escrita, a fala, o questionamento, um modelo explicativo, uma proposição didática.

Estes são alguns exemplos os quais se configuram como provisórios, limitados, passíveis de modificações, meios utilizados para se operar atividades em coletivo, sendo assim, buscamos compreendê-los para aperfeiçoá-los. Frente a isso, assumimos que o conjunto de atividades desenvolvidas na disciplina e esta como um todo pode ser considerada um objeto aperfeiçoável, com o qual professores em pesquisa-formação se transformam por estarem em atividade, modificando o ambiente de investigação. A disciplina desenvolvida e analisada se torna espaçotempo de pesquisa indissociável da formação. Para nós, a pesquisa tem papel formador no que tange aos professores envolvidos ativamente na disciplina, em virtude das diferentes indagações, proposições e negociações de significados no operar das atividades em coletivo.

Da mesma maneira, essa formação acontece ao estabelecermos diálogos investigativos com colegas diferentes e com interlocutores teóricos e ao comunicarmos compreensões. 0 objeto aperfeiçoável se transforma em espaço do coletivo de professores ao propormos a construção e o desenvolvimento da disciplina de forma colaborativa. Este é um espaçotempo de oportunizar transformações das práticas propostas e dos sujeitos envolvidos pelo movimentar em "espiral das compreensões, informações, experiências, construção do conhecimento" em sala de aula online (WELLS, 2009, p. 289).

Significamos o "operar", a partir de Leontiev (2012, p. 74), como "[...] modos de execução de um ato, conteúdos necessários de qualquer ação, mas não idênticos a ela", sendo este dependente "[...] das condições em que o alvo das ações é dado, enquanto uma ação é determinada pelo alvo" (LEONTIEV, 2012, p. 74). Nesse contexto, o operar da disciplina envolve ações internas e externas dos professores em pesquisa-formação na busca de compreenderem e atuarem em atividades da experimentação em Ciências na EaD.

O operar emerge, nos professores em processo de pesquisa-formação online, "[...] determinado pela tarefa, isto é, o alvo, dado em condições que requerem certo modo de ação" (LEONTIEV, 2012, p. 74). Exemplo disso é o professor que, envolvido na disciplina, tem o propósito de compreender o que são os fóruns na plataforma Moodle. Portanto, esse professor assume como "alvo" compreender estes respectivos espaços. Para atingir seu propósito, o professor poderá desenvolver a leitura de um texto que fale sobre "fóruns na plataforma Moodle"; ou ainda optar por participar dos fóruns no ambiente virtual da disciplina. Nos dois casos, a ação está em compreender o que são fóruns na plataforma Moodle, mesmo que executados por meios diferentes. Assim, o "operar", na busca de compreender, acontece de formas distintas.

A proposição de imersão dos sujeitos na linguagem em sala de aula online acontece pela comunicação interativa entre os professores na pesquisa-formação, em que o sujeito mais experiente "valoriza e possibilita o diálogo e a colaboração entre os participantes da aprendizagem" (SILVA, 2006, p. 29). Nessa perspectiva, apostamos nos sujeitos participantes em rede colaborativa de construção da investigação e não em uma rota única e definida por um transmissor. A aprendizagem e a avaliação acontecem durante o percurso, ao experienciarmos o 
movimento de expressar pensamentos, na corresponsabilidade de colaborar com o coletivo, de criar e cocriar proposições e avaliações. Todos os participantes colaboram e são fundamentais na definição da dinâmica conectiva e colaborativa que se estabelece no ambiente investigativo em torno do operar o objeto aperfeiçoável.

Observamos o conjunto das ações coletivas dos professores acontecer com e pela apropriação da linguagem no operar a disciplina como objeto aperfeiçoável. Nesse sentido, as ações expressas pelos sujeitos emergem como formas de registros da pesquisa-formação. Entre estes, estão os pensamentos escritos pelos professores em postagens de textos semanais sobre compreensões em torno das atividades experimentais de Ciências em cursos EaD. Tais registros se tornam passíveis de análise investigativa a partir do ambiente virtual da plataforma Moodle, onde observamos o uso de interfaces como fóruns, chats, Wikis, webconferência, vídeos, simuladores virtuais. Nesses espaços, estão expressos modelos explicativos, fenômenos da natureza, indagações dialógicas, proposições de atividades a serem desenvolvidas, bem como sugestões de leituras.

Assim, entendemos o ambiente da disciplina como um objeto aperfeiçoável proposto e desenvolvido por um coletivo de professores de Ciências imersos na linguagem. Esse coletivo expressa ações na busca de compreender a experimentação em Ciências na EaD e atuar nela. Essas ações são trazidas em diálogos, no compartilhar de experiências, nas estratégias, nos artefatos, nas atividades propostas e nas interfaces como registros, sendo suscetíveis de análise na pesquisa-formação online. Constituem-se como possíveis evidências empíricas, instigam e desafiam a proposição de uma metodologia de análise com base nas compreensões, informações, experiências e a construção do conhecimento expressas pelo coletivo de professores em torno do objeto aperfeiçoável.

\section{EVIDÊNCIAS EMPÍRICAS INICIAIS DO OPERAR OBJETO APERFEIÇOÁVEL}

Apresentamos o desenvolvimento das evidências empíricas iniciais nessa investigação ao descrevermos a experiência vivida de operar no coletivo de professores de Ciências na disciplina em EaD. Nosso primeiro movimento foi o de analisar os registros expressos na plataforma Moodle e no portfólio dos pesquisadores, que continham proposições desses sujeitos sobre temáticas, uso de artefatos, interfaces tecnológicas e diferentes atividades desenvolvidas ao longo do semestre. Nesse sentido, nossa descrição dos registros busca evidências para compreender como os sujeitos em coletivo desenvolvem/compreendem a disciplina de experimentação em Ciências na EaD - nessa investigação, o objeto aperfeiçoável.

Descrevermos a experiência vivida é, nessa pesquisa qualitativa, uma das maneiras de compreendermos, enquanto pesquisadores, o "fenômeno situado" ${ }^{7}$. Assumimos a descrição como forma de relatar diretamente a experiência do coletivo "[...] em situação de vivenciar o fenômeno focado e destacado como importante em relação à interrogação formulada, esta também interpretada como relevante no contexto da região do inquérito do pesquisador"

\footnotetext{
7 "Fenômeno situado - dedica os estudos disso que se mostra quando perguntamos pelo o que é isso que se mostra? Mas aquilo que se mostra, não se mostra, nem poderia, conforme a concepção fenomenológica, mas se revela na experiência vivida..." (BICUDO, 2011, p. 55).
} 
(BICUDO, 2011, p. 55). Nessa descrição, focamos nossa atenção no desenvolver/compreender da experimentação em Ciências na EaD pelo grupo de professores na disciplina.

A análise no AVA Moodle oportuniza-nos descrever a estruturação da proposta na oferta da disciplina. Na primeira semana de atividades, aconteceu o encontro presencial na universidade de todos os sujeitos envolvidos nesse contexto. Nesse encontro, ocorreram diálogos sobre como planejar a disciplina, com enfoque em construirmos o espaço do coletivo de professores em Ciências, a fim de que este seja um ambiente investigativo sobre a experimentação em Ciências frente à iminente oferta do curso de Licenciatura em Ciências na modalidade a Distância da FURG. Compreendemos que a disciplina é espaçotempo para o coletivo propor, indagar, teorizar e experienciar atividades de experimentação em Ciências na modalidade a distância com o auxílio das interfaces da internet.

Ao descrevermos os aspectos estruturais da experiência vivida no propor e no desenvolver da disciplina, expressamos compreensões iniciais em torno do objeto aperfeiçoável. Dessa forma, optamos pela perspectiva da pesquisa qualitativa fenomenológica hermenêutica e, assim "os significados que o pesquisador pode compreender nas descrições não se mostram de imediato, de modo direto, mas vão se revelando mediante a compreensão do sentido das experiências vividas pelo sujeito, olhadas na sua totalidade" (BICUDO, 2011, p. 56).

Essas compreensões escritas, portanto, são movimentos de idas e vindas na busca por significar e dar sentidos para o desenvolver/compreender das ações expressas nas diferentes semanas da disciplina. Na primeira semana de atividades do coletivo de professores, apresentamos a plataforma Moodle como um dos ambientes de aula da disciplina. Os participantes são instigados a escrever no fórum intitulado "Atividade Clássica" alguma atividade experimental presencial que tenha sido marcante na sala de aula de Ciências. Nessa tarefa, os sujeitos descrevem sobre como a desenvolveriam e como a transformariam em uma atividade na modalidade a distância. No sentido de teorizar e questionar tais atividades experimentais, o coletivo de professores se propõe a sugerir textos teóricos para a biblioteca virtual da disciplina, bem como, responsabiliza-se semanalmente por postar uma escrita individual contendo suas percepções frente à experimentação em Ciências na EaD.

Na segunda semana, um dos colegas propõe uma atividade experimental a ser desenvolvida pelo grupo em encontro presencial. A aula, que acontece em tempo real via webconferência, é gravada e promove a interação síncrona do coletivo com um dos professores que está em outra sala da Universidade e com um dos sujeitos que se encontra em sua casa. 0 professor proponente da atividade providencia o material a ser utilizado pelos colegas presenciais e pelo professor que está em outra sala da Universidade. O colega que está em casa não tem material para desenvolver o experimento, dialoga com o grupo, questiona e descreve seus modelos, interagindo com o coletivo através da escrita, fala e escuta.

$\mathrm{Na}$ respectiva aula presencial, os professores desenvolvem o experimento com seringas de plástico, água e ar a partir das orientações iniciais do colega e pelos questionamentos que surgem no grupo. Os colegas que estão presentes na atividade, quando querem fazer colocações, pedem o microfone e se dirigem à câmera de vídeo. O professor, em outra sala da Universidade, realiza o experimento, questiona, escuta, observa e dialoga com todos ao expor explicações sobre os fenômenos investigados. Todos os participantes são instigados a representar, através de desenhos, seus modelos explicativos e dialogar sobre eles no grupo. Em atividade síncrona, via 
fórum, os sujeitos efetuam, ao longo da semana, a segunda escrita e postagem sobre suas percepções frente à experimentação em Ciências na EaD.

Na terceira semana da disciplina, propomos, enquanto sujeitos imersos no ambiente da pesquisa-formação, uma aula sobre as possibilidades da webconferência em atividades síncronas e assíncronas. Pensamos nisso, pois, na segunda semana da disciplina, emergem questionamentos sobre esta interface, em virtude de esta ter propiciado a participação de uma colega acidentada que estava em sua casa. Sendo assim, a referida aula se tornou um pedido do coletivo de professores frente ao desafio e às possibilidades do referido artefato na EaD. A ênfase da atividade desenvolvida se centra na apropriação tecnológica do software Adobe Connect para o contexto educativo. Realizamos uma aula síncrona com alguns dos colegas presentes no laboratório de informática da Universidade e com outros em diferentes locais, como em salas de permanência, em casa e em outros espaços da Universidade.

Na referida aula, envolvemos os sujeitos no experienciar da webconferência a partir das ferramentas do software citado. Esta prática foi gravada e, posteriormente, disponibilizada como vídeo para todos os participantes. Os sujeitos foram instigados a falar no microfone, escutar e observar as reações ante a webcam. Compartilhamos apresentações, tela do computador, imagens, vídeos e, também, comunicamo-nos via bate-papo. Ainda durante essa semana, desenvolvemos, de forma assíncrona, a terceira escrita e postagem no ambiente Moodle. Um dos colegas, professor da disciplina, assume a proposição das atividades a serem desenvolvidas na quarta semana da disciplina. Ao longo desse período, o sujeito informa ao grupo data e hora da atividade experimental a ser desenvolvida via webconferência de forma síncrona. Solicita que cada colega professor providencie régua, cronômetro e que o grupo se organize em duplas para a execução das atividades.

Durante esse encontro via webconferência, as duplas foram desafiadas a medir o tempo de reação com o soltar e pegar de uma régua. Cada dupla organizou os dados em tabela e desenvolveu a média do tempo de reação. O diálogo entre o coletivo é instigado ao interagirmos por meio de fala, vídeo e bate-papo no Adobe Connect, e, assim, questionarmos a proposta e os modelos explicativos para o fenômeno do tempo de reação das pessoas. As tarefas em torno do experimento foram disponibilizadas na forma de videoaula, em hyperlink com a gravação da webconferência no ambiente virtual. Nessa ocasião, cada participante escreve e posta o quarto texto semanal. Na atividade da quinta semana, apresentamos material prévio na referida plataforma e organizamos as atividades em quatro etapas, as quais tiveram momentos síncronos e assíncronos, com horários e prazos estabelecidos para a entrega das ações propostas.

Primeiramente, desafiamos o grupo a trabalhar com o vídeo disponível na internet Vídeo Estufa Solar e a secagem de Grãos (2011) - e dialogamos em fóruns os modelos explicativos a partir de questões norteadoras iniciais. Em um segundo momento, instigamos os sujeitos a interagirem com o simulador virtual da University Colorado At Boulder - Efeito Estufa (2011). Além disso, promovemos a troca de significados em fóruns sobre os fenômenos e modelos explicativos representados no simulador e organizamos um espaço em chat para tirarmos dúvidas sobre o uso dessa ferramenta. No terceiro momento, propiciamos a interação via Adobe Connect (SEaD/FURG, 2011) com o propósito de indagar sobre as atividades realizadas e analisar as possibilidades de desenvolver a experimentação em modo síncrono e assíncrono. Logo após, no quarto momento, o coletivo de professores realiza a escrita semanal e postagem 
dos textos sobre as atividades, contendo suas percepções em torno da experimentação em Ciências na EaD.

A necessidade de teorizar as práticas desenvolvidas na disciplina é uma das demandas sentidas e expressas pelo grupo na webconferência da quinta semana de atividades. Assim, um dos colegas do grupo estrutura e propõe os períodos da sexta e sétima semana, com desafio de teorizar a experimentação no ensino de Ciências. Cada sujeito participa da produção de unidades de significado em uma Wiki coletiva. Inicialmente, a escrita das unidades é realizada por meio das primeiras compreensões sobre a experimentação em Ciências de cada professor participante. Depois, somos desafiados a desenvolver leituras de textos teóricos sobre a experimentação em Ciências, disponibilizados na biblioteca virtual. A partir destas, escrevemos outras unidades de significado.

Durante essas duas semanas de atividades, fomos incitados a escrever e postar metatexto sobre uma das temáticas da experimentação em Ciências que veio à tona ao construirmos coletivamente a Wiki. Observamos que todas as atividades desenvolvidas nas referidas semanas foram assíncronas e orientadas via plataforma Moodle. Postamos também a sexta escrita sobre nossas percepções em torno das práticas experimentais em Ciências. Na oitava semana, o coletivo de professores foi convidado a participar de um debate presencial, intitulado "experimentação em Ciências na Educação Básica", desenvolvido no 31 ㅇ Encontro de Debates da Educação Química - EDEQ, promovido pela FURG. Então, postamos a sétima produção sobre a experimentação em Ciências articulada aos entendimentos construídos com base no debate.

Nós, sujeitos da disciplina Experimentação em Ciências na EaD, participamos, durante a nona semana de atividades, do "Encontro para ações em EaD" promovido e organizado pela SEaD da FURG. Acompanhamos os diálogos de duas mesas sobre diferentes temáticas a respeito da "escrita" e "avaliação" em EaD. Na plataforma Moodle, foram abertos dois fóruns assíncronos. No primeiro, fomos instigados a discutir sobre o papel da avaliação no ensino e na aprendizagem de atividades experimentais em EaD - destinado ao grupo que participou da referida mesa. No segundo, o grupo que participou da mesa temática "escrita em EaD" foi convidado a dialogar sobre o papel da escrita nas atividades experimentais em EaD.

Ao chegarmos à décima semana da disciplina, desenvolvemos atividades de forma assíncrona via Moodle, organizadas em fóruns previamente estruturados a partir de orientações sobre o que desenvolver. 0 primeiro fórum propõe aos sujeitos que criem e socializem com o coletivo uma atividade experimental para ser realizada com o grupo de estudantes do futuro curso de Licenciatura em Ciências, explorando as possibilidades presentes no uso de ferramentas das TIC. A partir dessa socialização, os sujeitos em pesquisa-formação foram convidados, em fórum específico, a auxiliar os demais colegas com indagações, referenciais e sugestões. No segundo fórum, avaliamos o desenvolver da disciplina de Experimentação em Ciências na EaD. 0 respectivo fórum nos instiga a expressar potencialidades, fragilidades e sugestões percebidas no decorrer das atividades na disciplina, bem como, desafia-nos a relatar percepções sobre como o envolvimento nas ações da disciplina contribui na formação profissional.

A escrita recursiva sobre as proposições de atividades, os recursos tecnológicos e as temáticas constitui evidências empíricas iniciais, tornando-se estrutura para as propostas e o desenvolvimento do objeto aperfeiçoável. Compreendemos, até aqui, este como espaçotempo investigativo e formativo construído pelos participantes ao longo do semestre de forma coletiva, 
colaborativa, interativa e flexível. As predefinições iniciais foram redefinidas a partir das colaborações dos sujeitos durante as diferentes ações desenvolvidas frente às atividades. Nesse sentido, analisamos o movimento coletivo dos professores ao assumirem corresponsabilidade no ambiente investigativo online em torno da temática experimentação em Ciências.

Esta descrição inicial oportuniza-nos compreender a disciplina como espaçotempo de pesquisa-formação online do coletivo dos professores de Ciências. Em virtude disso, emerge o significado da pesquisa-formação, nesse "contexto educativo online" (SILVA; SANTOS, 2006; SILVA, 2012), no sentido de estarmos imersos na linguagem, na cocriação de comunicação e no conhecimento enquanto professores em ambiente investigativo e formativo. Estruturamos, assim, um meio coletivo com diferentes professores, ao oportunizarmos formas de expressar ações de modo individual e coletivo. Esse movimento é oportunizado por diversas ferramentas tecnológicas da web 2.0, como: ambiente virtual Moodle, webconferências, Wikis, fóruns, chats, vídeos, simuladores, fotos, hyperlinks, textos e apresentações. Nessa perspectiva, a Experimentação em Ciências na EaD possibilita-nos analisar as ações do grupo de docentes por meio dos registros das interações entre os sujeitos nas atividades online e por estarmos imersos na linguagem com diferentes interlocutores.

No contexto da escrita recursiva, deparamo-nos com o questionamento sobre como analisar e complexificar os significados das ações coletivas dos professores no desenvolver/compreender a experimentação em Ciências na EaD. Ao tratarmos a investigação como pesquisa qualitativa de cunho fenomenológico hermenêutico, somos desafiados a ficar "[...] atentos aos momentos de análise e procedimentos indicados, não os tomando como uma sequência linear e hierárquica" (BICUDO, 2011, p. 59). Sendo assim, sentimos a necessidade de buscar o caminho metodológico que possibilite movimentar as compreensões, as informações, as experiências e a construção do conhecimento, todas estas envolvidas no objeto aperfeiçoável. Poderemos, então, desenvolver e expressar pela linguagem argumentos compreendidos sobre esse ambiente investigativo transformador das práticas sociais propostas e dos sujeitos envolvidos.

\section{COMPLEXIFICAR ARGUMENTOS EM BUSCA DE COMPREENDER A EXPERIMENTAÇÃO EM CIÊNCIAS NA EAD COM BASE NA LINGUAGEM}

Com a intencionalidade de complexificarmos argumentos sobre a experimentação em Ciências na EaD, somos instigados, enquanto pesquisadores, a definir um caminho metodológico de análise que oportunize expressar, com base na linguagem, o que nos foi compreendido. Tratase de mergulharmos na Análise Textual Discursiva das informações produzidas pelos sujeitos no ambiente investigativo do objeto aperfeiçoável. A ATD é uma metodologia de análise de informações de natureza qualitativa com a finalidade de produzir diferentes entendimentos sobre os fenômenos e discursos investigados (MORAES; GALIAZZI, 2011, p. 7).

Desenvolvemos a escrita recursiva pela ATD a partir de compreensões expressas em forma de texto. Em um primeiro movimento, conforme as descrições da experiência vivenciada, evidenciamos os espaços nos quais encontramos a linguagem expressa pelo coletivo de sujeitos ao participarem da disciplina de Experimentação em Ciências na EaD. Encontramos os registros organizados no ambiente Moodle, nas interfaces utilizadas em atividades semanais e em registros nos portfólios dos pesquisadores. Visualizamos diferentes diálogos escritos nos 
processos de interação entre os sujeitos, ocorridos em fóruns, chats, Wikis, bem como no texto proposto sobre o experienciar as atividades desenvolvidas e a experimentação em Ciências na EaD. As falas dos sujeitos na webconferência, gravadas e disponibilizadas em hyperlink no ambiente virtual da disciplina, são outra forma de registro.

A linguagem expressa pelo coletivo de professores participantes da disciplina constitui o conjunto de evidências empíricas a ser sistematizado e organizado na investigação. Na ATD, independentemente da sua origem, as informações analisadas necessitam ser transformadas em documentos escritos para, então, serem submetidos à análise. Produzimos unidades de significado escritas e codificadas a fim de organizar as informações investigadas. Este é um espaçotempo de ampliarmos pensamentos sobre a experiência vivida, ao possibilitarmo-nos “insights, abstrações, comparações, articulações, reunindo e separando aspectos, expressando o compreendido pela linguagem, quando obtemos clareza e ficamos em dúvida, enfim são movimentos do pensar ao percorrer os meandros do pensamento investigativo" (BICUDO, 2011, p. 59).

Nessa perspectiva, assumimos a "escrita como princípio de pesquisa" (MARQUES, 2008), como uma forma de complexificar argumentos em torno da temática em estudo. Assim, concebemos esta como ferramenta epistêmica para entendermos de que forma a comunidade de pesquisa-formação online de professores de Ciências desenvolve/compreende a experimentação na EaD. Com base nos conceitos de Vigostski (2008, 2012), consideramos a linguagem uma ferramenta psicológica, "[...] algo que é utilizado por cada um de nós para atribuir sentido à experiência" (MERCER, 1998, p. 14). Sendo assim, desenvolvemos os textos, assumindo "[...] que nem os instrumentos ou os artefatos e nem os conhecimentos e as práticas associadas a eles seriam possíveis sem o mais poderoso e versátil instrumento intelectual de todos: a linguagem humana" (WELLS, 1998, p. 112).

O processo de compreender a linguagem expressa pelo coletivo que opera o objeto aperfeiçoável desafia os pesquisadores à imersão no diálogo investigativo, na ressignificação das questões e nas compreensões atribuídas às questões iniciais que norteiam a temática. Argumentamos, a partir de Galiazzi (2011), que, em ambiente de pesquisa, não basta apenas estabelecermos um bom clima de diálogo entre os sujeitos, faz-se necessário constituirmos um coletivo aprendente com "[...] diálogo crítico, que se constrói e reconstrói pelo exercício sistemático e sempre repetido da escrita, da leitura, para chegar à contraleitura, da argumentação pelo diálogo crítico" (GALIAZZI, 2011, p. 63).

Dessa maneira, o compreender dos desafios presentes na pesquisa acontece pela imersão na linguagem que constitui os diferentes discursos expressos no ambiente coletivo da experimentação em Ciências online. Esta é a forma de dialogar criticamente com as falas e escritas dos sujeitos em busca de diferentes interlocutores. A escrita oportuniza que os sujeitos exponham questionamentos e troquem significados e hipóteses com a intenção de produzir sentido para suas experiências por meio da argumentação sobre o que ocorre na pesquisaformação online. Nessa perspectiva, o escrever se constitui em um importante artefato epistêmico (Wells, 1999), com o qual os sujeitos pesquisadores do coletivo aprendente podem evidenciar a construção de significações em torno do tema em estudo.

De acordo com as concepções de Marques (2008), assumimos o escrever como um artefato mediador do pensar, que encaminha a leitura em busca de interlocutores que auxiliem 
no desenvolvimento da argumentação. A escrita recursiva associada ao ler possibilita integrar em diferentes textos argumentos iniciais, insights, compreensões e significados emergentes do coletivo em pesquisa-formação. Também oportuniza confrontar outros conhecimentos e outras falas provenientes de leituras e de vozes coletivas, que se desvelam aos pesquisadores durante 0 processo de escrita. Consideramos esse momento, a partir de Marques (2008), como espaçotempo de diálogo com os interlocutores do texto em construção e como movimentos recursivos de desenvolver argumentação, que encaminham e possibilitam o estabelecimento de redes investigativas.

Diante disso, emergem os questionamentos de como sistematizarmos e organizarmos a escrita recursiva nessa proposição metodológica de maneira a possibilitar a articulação de evidências empíricas e teóricas no diálogo com diferentes interlocutores a partir das experiências vividas pelos pesquisadores na experimentação em Ciências na EaD. Nessa perspectiva, apresentamos o exemplo de como sistematizamos e organizamos essa escrita recursiva de modo a oportunizar a análise das informações geradas e a emergência de outras compreensões em torno do tema investigado.

Nesse momento, demonstraremos a análise desenvolvida pela ATD em torno das atividades propostas e realizadas na quinta semana da disciplina como forma de explicitar o caminho metodológico proposto na investigação. As linguagens expressas em forma de diálogos foram obtidas nos fóruns, nos chats, na webconferência e no texto semanal escrito por cada um dos sujeitos em pesquisa-formação, o que constituiu as evidências empíricas nessa investigação em que as ações foram mapeadas e escritas para posterior análise através da ATD.

Desenvolvemos essa primeira análise a partir da quinta semana, pois, nesta, fomos os responsáveis por estruturar as atividades desenvolvidas pelo coletivo de professores no ambiente virtual online. As tarefas foram propostas com os objetivos de operar sobre a temática do efeito estufa; oportunizar diálogo entre sujeitos sobre os fenômenos da natureza e ressignificar modelos explicativos para este assunto; além de oportunizar interlocuções sobre as potencialidades e as limitações ao fazermos uso de vídeos e simuladores virtuais na experimentação em Ciências; analisar coletivamente os resultados, as limitações das atividades e a emergência de proposições do grupo.

Ressaltamos que essas evidências empíricas, verificadas a partir da quinta semana, são perpassadas pelos aspectos da ontogenia, pelas perspectivas históricas da experimentação em Ciências na EaD, pelos aspectos socioculturais da EaD e pelo movimentar da linguagem do coletivo de professores. Nesse sentido, surge o escrever como princípio de pesquisa com diferentes interlocutores, no qual envolvemos compreensões, informações, experiências e construções de conhecimentos no ambiente investigativo do objeto aperfeiçoável.

Tabela 1 - Recorte das unidades de significado e suas codificações na planilha eletrônica 


\begin{tabular}{|c|c|c|c|c|c|}
\hline \multicolumn{6}{|c|}{ Processo de ATD com as Unidades de Significado (Fóruns, escrita, webconferência, teóricos e construção dos autores) } \\
\hline Código da unidade & Unidades de significado & Palavras-chave & Titulo & \begin{tabular}{|c|} 
Código da \\
categoria inicial
\end{tabular} & \begin{tabular}{|c|} 
Código da \\
categoria final
\end{tabular} \\
\hline A1 & $\begin{array}{l}\text { faz-se necessário distinguir e definir o que assumimos como fenômeno da } \\
\text { natureza e modelo explicativo. "O fenômeno pode ser mostrado, pois é o } \\
\text { acontecimento da natureza", enquanto que o modelo explicativo "não está } \\
\text { diretamente visível, é uma abstração que precisa ser construída } \\
\text { logicamente pelos sujeitos envolvidos na ação do experimentar na } \\
\text { Educação em Ciências (CARVALHO,2010, p.64). }\end{array}$ & $\begin{array}{c}\text { fenômeno da natureza, } \\
\text { modelo explicativo, } \\
\text { abstração }\end{array}$ & $\begin{array}{l}\text { A construção dos } \\
\text { modelos explicativos } \\
\text { sobre os fenômenos da } \\
\text { natureza implica e } \\
\text { abstração e construção } \\
\text { lógica }\end{array}$ & A & 1 \\
\hline A2.A5.4R. & $\begin{array}{l}\text { Passamos novamente aos fóruns e continuamos nossas discussões sobre a } \\
\text { temática do Efeito Estufa, muitas apostas levantadas anteriormente foram } \\
\text { refutadas e reformuladas. Este foi um processo muito significativo na aula, e } \\
\text { a possibilidade de percebermos as compreensões sendo revisitadas e } \\
\text { problematizadas gerando com isto novas percepções. }\end{array}$ & $\begin{array}{l}\text { Diálogo recursivo, } \\
\text { fóruns, modelo } \\
\text { explicativo, } \\
\text { ressignificação }\end{array}$ & $\begin{array}{l}\text { O diálogo recursivo em } \\
\text { fóruns proporciona a } \\
\text { ressignificação dos } \\
\text { modelos explicativos }\end{array}$ & C & 1 \\
\hline A14 & $\begin{array}{l}\text { O uso de simuladores para realizar a experimentação, necessita ampliar o } \\
\text { debate em torno do experimento, de modo a oportunizar espaços para a } \\
\text { investigação, transformação e reconstrução dos modelos explicativos dos } \\
\text { sujeitos, onde a "simulação é uma mediação distinta, pois relaciona os } \\
\text { fenômenos macroscópicos e sub-microscópicos, em uma construção teórica } \\
\text { que nem sempre encontra sustentaçãa empírica para medições" (GIORDAN, } \\
2008, \text { p. 190). }\end{array}$ & $\begin{array}{l}\text { simulador, } \\
\text { experimentação, } \\
\text { ambiente investigativo } \\
\text { transformação e } \\
\text { reconstruçấo dos } \\
\text { modelos explicativos, } \\
\text { mediação } \\
\end{array}$ & $\begin{array}{l}\text { O uso de simuladores } \\
\text { oportuniza a mediação na } \\
\text { experimentação de } \\
\text { evidência empiricas para } \\
\text { reconstrução dos } \\
\text { modelos explicativos }\end{array}$ & $\mathrm{E}$ & 2 \\
\hline SG. A5.FS & $\begin{array}{l}\text { Concordo contigo colega. O simulador é bem interessante, mas acaba } \\
\text { abrangendo muitos assuntos ao mesmo tempo. Não sei até que ponto } \\
\text { conseguiria utilizá-lo sem ficar presa num cronograma de ações que os } \\
\text { alunos devem executar. }\end{array}$ & $\begin{array}{c}\text { conceitos presentes no } \\
\text { simulador, } \\
\text { planejamento fechado, }\end{array}$ & $\begin{array}{l}\text { O uso de simuladores } \\
\text { virtuais envolve o planejar } \\
\text { ações que envolvam } \\
\text { diferentes conceitos }\end{array}$ & $\mathrm{F}$ & 3 \\
\hline VC & $\begin{array}{l}\text { enfatizamos que atividades experimentais, desafiam os sujeitos a } \\
\text { desenvolverem a argumentação, estruturando-a pela e com as diferentes } \\
\text { linguagens que constituem a Ciência e o como estas se relacionam com os } \\
\text { contextos sociais, históricos e tecnológicos }\end{array}$ & $\begin{array}{c}\text { atividades } \\
\text { experimentais, desafio, } \\
\text { desenvolver, argumento }\end{array}$ & $\begin{array}{l}\text { As atividades } \\
\text { experimentais precisam } \\
\text { desafiar os sujeitos a } \\
\text { desenvolver a } \\
\text { argumentação } \\
\end{array}$ & G & 3 \\
\hline
\end{tabular}

As evidências empíricas em conjunto com interlocuções teóricas e registros do coletivo de professores foram estruturadas em unidades de significado e codificadas a fim de preservar 0 direito autoral dos interlocutores da pesquisa, conforme a tabela 1. As informações desenvolvidas e organizadas nessa tabela formam o corpus de análise do operar o objeto aperfeiçoável na quinta semana. Procedemos o movimento da construção das referidas unidades de significado com o auxílio de planilha eletrônica, por esta possibilitar-nos sistematizar, codificar e organizar o trabalho de escrita recursiva com o referido corpus de análise.

A análise das informações através da ATD possibilita aos pesquisadores imersão no compreender o fenômeno da experimentação em Ciências. Esta é uma forma de construir as palavras escritas e dar sentido a elas nas unidades de significado. Dessa forma, na escrita recursiva, emergem sete subcategorias para a compreensão do fenômeno investigado, descritas na tabela 2 como categorias iniciais.

Tabela 2 - Códigos e expressões das categorias iniciais interligados ao código da categoria final

\begin{tabular}{|c|l|c|}
\hline Código & \multicolumn{1}{|c|}{ Categoria Inicial } & Código da categoria final \\
\hline A & $\begin{array}{l}\text { Compreender os fenômenos da natureza envolve os sujeitos na construção de } \\
\text { modelos explicativos com e pela linguagem }\end{array}$ & 1 \\
\hline C & $\begin{array}{l}\text { O diálogo investigativo no coletivo de professores em formação possibilita a } \\
\text { construção de modelos explicativos }\end{array}$ & 2 \\
\hline B & $\begin{array}{l}\text { A diversificação de artefatos na experimentação potencializa a problematização e } \\
\text { os diálogos sobre as temáticas da Ciência }\end{array}$ & 2 \\
\hline E & $\begin{array}{l}\text { A atividade humana é mediada pelo uso e apropriação de ferramentas com as } \\
\text { quais os sujeitos se reconstroem }\end{array}$ & 3 \\
\hline D & $\begin{array}{l}\text { Desenvolver propostas metodológicas para Experimentação desafia aos } \\
\text { formadores considerar as individualidades no coletivo e a quantidade de } \\
\text { informaç̧̃es a serem ressignificadas pelos sujeitos }\end{array}$ & 3 \\
\hline F & $\begin{array}{l}\text { É desafio para a formação de professores oportunizar espaços de aproprição } \\
\text { tecnológica articulada ao planejamento e problematização da experimentação }\end{array}$ & 3 \\
\hline G & $\begin{array}{l}\text { Aprendizagem é um processo articulado a experiência do sujeito com a } \\
\text { transformação de seus argumentos }\end{array}$ \\
\hline
\end{tabular}


O movimento de construirmos subcategorias oportuniza-nos perceber como estas podem-se relacionar articuladas ao contexto da pesquisa, fazendo emergir redes de conceitos que possibilitem dar sentido e construir argumentos em torno do ambiente investigativo. Na tabela 3, exemplificamos a emergência das categorias finais para análise das informações produzidas, relacionadas à quinta semana de atividades da disciplina, associando evidências empíricas e teóricas.

Tabela 3 - Codificação e expressões das categorias finais

\begin{tabular}{|c|c|}
\hline Código da categoria final & Categoria final \\
\hline 1 & $\begin{array}{l}\text { Experimentação em Ciências online } \\
\text { envolve os sujeitos imersos na } \\
\text { linguagem no ressignificar modelos } \\
\text { explicativos }\end{array}$ \\
\hline 2 & $\begin{array}{l}\text { A apropriação de ferramentas } \\
\text { tecnológicas como mediadora do } \\
\text { desenvolvimento humano e } \\
\text { ressignificação dos discursos da Ciência }\end{array}$ \\
\hline 3 & $\begin{array}{l}\text { A experimentação em Ciências na } \\
\text { formação de professores online } \\
\text { mediado pelo planejar, apropriar } \\
\text { tecnológico e experienciar dos sujeitos }\end{array}$ \\
\hline
\end{tabular}

Desse movimento de análise das informações com escrita recursiva pela ATD, desenvolvemos o metatexto ${ }^{8}$. O referido metatexto é estruturado a partir das três categorias finais emergentes na análise, expressas na tabela 3. O processo de escrita do metatexto envolve intensa atividade de escrever, ler e dialogar com outros interlocutores, interligado ao movimento recursivo de ressignificar e reconstruir as unidades de significado da tabela 2. Para o exemplo descrito, são as categorias finais que oportunizam o emergir do argumento aglutinador a ser desenvolvido ao longo do metatexto. A Experimentação em Ciências na EaD na formação de professores envolve os sujeitos em pesquisa-formação online com o operar artefatos, diálogos e modelos explicativos imersos na linguagem.

A intensa escrita recursiva, pela Análise Textual Discursiva, possibilita aos pesquisadores complexificar argumentos sobre o desenvolver/compreender do coletivo de professores na experimentação em Ciências na EaD pela imersão na linguagem. $O$ diálogo com evidências empíricas e teóricas é processo de transformar as informações produzidas pelos sujeitos em pesquisa-formação em compreensões escritas. Nessa perspectiva, o conhecimento surge do mergulho na análise da linguagem do ambiente investigativo, isto é, dos sujeitos imersos no operar o objeto aperfeiçoável.

\section{COMPREENSÕES SOBRE O CAMINHO METODOLÓGICO PROPOSTO}

A escrita recursiva nessa investigação possibilita-nos propor este caminho metodológico como pesquisa qualitativa de cunho fenomenológico hermenêutico com base na linguagem. Assumimos a linguagem pelo viés sociocultural na busca de significar como se

\footnotetext{
${ }^{8}$ Experimentação em Ciências na EaD envolve professores no operar objeto aperfeiçoável em pesquisa-formação online - Metatexto comunicado no IX ENPEC, realizado na cidade Águas de Lindóia, SP, em novembro de 2013.
} 
desenvolve/compreende, a partir das ações coletivas dos professores, o operar do objeto aperfeiçoável. A análise das evidências empíricas iniciais neste estudo acontece pela imersão dos pesquisadores em diálogos com registros, proposições de temáticas, interfaces tecnológicas e atividades desenvolvidas pelos sujeitos em pesquisa-formação online.

Nesse contexto, a pesquisa-formação online emerge como corresponsabilidade de propor e desenvolver o objeto aperfeiçoável em coletivo de professores de Ciências. Este movimento possibilita o ampliar de informações, construção do conhecimento, experiências e compreensões ao mergulharmos nas linguagens expressas do ambiente investigado. Esse espaço contém registros do coletivo de professores, que expressam pensamentos, atividades experimentais, modelos, indagações, fenômenos da natureza, artefatos e interfaces. Entre os artefatos e as interfaces estão o ambiente virtual Moodle, as webconferências, as Wikis, os fóruns, os chats, os vídeos, os simuladores, as fotos, os hyperlinks, os textos e as apresentações. A linguagem expressa possibilita aos pesquisadores mergulharem na análise de informações produzidas pela ATD e complexificar os argumentos em torno do tema investigado.

Nesse contexto, a estrutura do caminho investigativo proposto é espaçotempo do pesquisador coletivo, de estar em pesquisa-formação online e, assim, possibilitar a transformação das práticas e dos sujeitos envolvidos na proposição, no desenvolvimento e na análise ao operarem com o objeto aperfeiçoável. Essa proposição metodológica assume a perspectiva da função epistêmica da escrita ao sistematizarmos, ressignificarmos e darmos sentido à experiência vivida com o auxílio das evidências empíricas e teóricas através dos diálogos com os diferentes sujeitos sobre a experimentação em Ciências na EaD.

\section{REFERÊNCIAS BIBLIOGRÁFICAS}

1. ALVES, N. Cultura e cotidiano escolar. Revista Brasileira de Educação, n.23, Rio de Janeiro, maio/jun./jul./ago. 2003.

2. BICUDO, M. A. V. Pesquisa Qualitativa segundo a visão fenomenológica. São Paulo: Cortez, 2011.

3. DINIZ-PEREIRA, J. E. O ovo ou a galinha: a crise da profissão docente e a aparente falta de perspectiva para a educação brasileira. Revista Brasileira de Estudos Pedagógicos, Brasília, v.92, n.230, 2011.

4. ___ _ LACERDA, M. P. Possíveis Significados da Pesquisa na Prática Docente: Ideias para fomentar o debate. Revista Educação e Sociedade. Campinas, v.30, n.109, Campinas, set./dez 2009.

5. GALIAZZI, M. C. Educar pela Pesquisa: ambiente de formação de professores de Ciências. ljuí: Unijuí, 2011.

6. LEONTIEV, A. N. Uma Contribuição à Teoria do Desenvolvimento da Psique Infantil. In: VIGOTSKI, Lev Semenovich et al. Linguagem, Desenvolvimento e Aprendizagem. 12 ed. São Paulo: Ícone, 2012.

7. MARQUES, M. O. Escrever é preciso: o princípio da pesquisa. 5.ed. ljuí: Unijuí, 2008.

8. MERCER, N. As perspectivas socioculturais e o estudo do discurso em sala de aula. In: COLL, César; EDWARDS, Derek. Ensino, aprendizagem e discurso em sala de aula: aproximações ao 
estudo do discurso educacional. Porto Alegre: Artmed, 1998.

9. MORAES, R.; GALIAZZI, M. C. Análise Textual Discursiva. ljuí: Unijuí, 2011.

10. MORAES, R. Aprender Ciências: reconstruindo e ampliando saberes. In: GALIAZZI, Maria do Carmo et al. (Orgs.). Construção Curricular em Rede na Educação em Ciências. Ijuí: Unijuí, 2007.

11. SEaD/FURG. Adobe Conecct: Webconferência da Aula de Experimentação. Disponível em: <http://videoconferencia.uab.furg.br/experimentacao/>. Acesso 04 set. 2011.

12. SILVA, M. (Org.). Formação de professores para a docência online. São Paulo: Edições Loyola, 2012.

13. _. O fundamento comunicacional da avaliação da aprendizagem na sala de aula online. In.: SILVA, Marco; SANTOS, Edméa (Orgs.). Avaliação da Aprendizagem em Educação Online. São Paulo: Loyola, 2006.

14. __ ; SANTOS, E. Avaliação da aprendizagem em educação online. São Paulo: Edições Loyola, 2006.

15. UNIVERSITY Colorado at Boulder. Efeito Estufa. Disponível em: <http://phet.colorado.edu/pt_BR/simulation/greenhouse>. Acesso 04 set. 2011.

16. VÍDEO Estufa Solar e a secagem de Grãos. Disponível em: <http://www.youtube.com/watch?v=QIR9S_7sJ80>. Acesso em 04 set. 2011.

17. VIGOTSKI, L. S. e. al. Linguagem, Desenvolvimento e Aprendizagem. 12.ed. São Paulo: Ícone, 2012.

18. __ Pensamento e Linguagem. 4.ed. São Paulo: Martins Fontes, 2008.

19. WELLS, G. Da Advinhação à Previsão: discurso progressivo no ensino e na aprendizagem de Ciências. In: COLL, César; EDWARDS, Derek. Ensino, aprendizagem e discurso em sala de aula: aproximações ao estudo do discurso educacional. Porto Alegre: Artmed, 1998.

20. ___ Indagación Dialógica: Hacia una teoría y una práctica socioculturales de la educación. Buenos Aires: Editorial Paidós, 2001.

21. __. The Meaning Makers: Learning to Talk and Talking to Learn. 2.ed. U.K: Bristol, 2009.

22. _. Dialogic inquiry: towards a sociocultural practice and theory of education. New York: Cambridge University Press, 1999. 